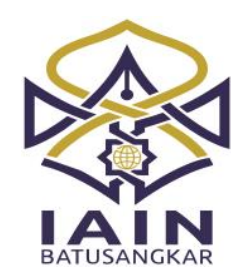

JURNAL TA'DIB, Vol 23 (1), 2020, (Januari-Juni)
ISSN: 1410-8208 (Print) 2580-2771 (Online)
Tersedia online di http://ecampus.iainbatusangkar.ac.id/ojs/index.php/takdib/index

\title{
Moderasi Pendidikan Pesantren di Kalimantan Timur
}

\author{
Khojir *) \\ Institut Agama Islam Negeri Samarinda, \\ Kalimantan Timur, Indonesia \\ E-mail: khojir@iain-samarinda.ac.id
}

\begin{abstract}
This article discusses the efforts of Islamic boarding schools to form educational moderation, models of moderation and the implications of pesantren education moderation. The design of this study was qualitative with a theological and pedagogical approaches. The informants of this research wre the leaders, religious teachers, administrators, and students. Furthermore, the data were collected through interviews, observations and documentation. To test the validity of the data, triangulation of data was performed. Data analysis was carried out in three stages, namely: reduction, presentation and conclusion drawing from the data. The findings of this study were; first, the pesantren efforts in shaping education moderation by socializing all forms of extremism and radicalism to the studensts, choosing teaching materials or books that are free from extremist values and radicalism, designing moderate curriculum and learning methods. Second, the education moderation model that integrates learning and collaboration with the life of pesantren. Third, the implications of educational moderation for pesantren were in forms of; positive community assessments of pesantren, increasingly moderate community, and making pesantren as a reference for the community.
\end{abstract}

Keywords: Moderation, Education, Pesantren and Radicalism

$\mathrm{M}$

HULUAN

oderasi beragama akhir-akhir ini menjadi pembicaraan yang sangat serius di kalangan pemerintah maupun akademisi. Bahkan beberapa tokoh dunia seperti Raja Salman, Donald J. Trump sering menyebut istilah "moderasi" beragama sebagai lawan "radikalisme", termasuk Menteri Agama (Lukman Hakim Syaifuddin) sering menyampaikan persoalan yang sama dalam berbagai sambutannya. Rapat Kerja Nasional tahun 2019 Kementerian Agama mengusung tema "moderasi beragama".

Perhatian beberapa tokoh dunia dan pemerintah Indonesia bukan tanpa alasan, setidaknya terdapat beberapa peristiwa baik internasional maupun nasional yang telah terjadi. Skala internasional seperti terjadinya ketegangan Palestina-Israel sejak 1948 yang ramai diberitakan media (Herman and Nurdiansa, 2010), invasi Irak atas Kuwait (1990) yang melahirkan perang Teluk, munculnya isu Sunnah-Syiah yang dipolitisasi, kebijakan Donald Trump memindahkan Ibu Kota Israel ke Yerusalem, kasus pengebomam gedung Word Trade Center (WTC) New York Amerika Serikat tanggal 11 September 2001 yang diduga dilakukan oleh al-Qaedah, konflik Syiria yang berkepanjangan dengan munculnya negara Islam yaitu Islamic State of Iraq and Syria (ISIS).

Dalam skala nasional beberapa aksi terorisme telah terjadi seperti Bom Bali (2002), Plaza Sarinah (2016), peledakan bom di gereja Loa Janan Samarinda (2016), dan kasus bom bunuh diri pada tiga gereja di Surabaya (2017). Maraknya gerakan-gerakan yang dilakukan oleh ormas Islam seperti 
Hizbut Tahrir Indonesia (HTI), Jamaah Salafi, Majelis Mujahidin, Jamaah Anshar alTauhid, Front Pembela Islam (FPI), Pesantren Ngruki, Laskar Ahl Sunnah wa alJamaah, dan Ikhwanul Muslimin (Sulistyo, 2018). Beberapa kasus tersebut masih ditambah lagi terjadinya intoleran Islamis di beberapa daerah di Indonesia (Azca, Ikhwan and Arrobi, 2019).

Di era milenial, radikalisme dan terorisme perkembangannya cukup pesat yaitu melalui media internet sebagai alat propaganda untuk menarik simpati. Seperti kasus di Amerika sebagaimana hasil temuan Brian Levin, bahwa Salafi ekstrimis menggunakan media online, internet sebagai alat meradikalisasi anak-anak muda (Levin, 2015). Hasil riset ini sebetulnya mempunyai nilai strategis di era milenial terkait dengan perkembangan teknologi, sehingga memperkuat pernyataan bahwa media online mampu menguasai kondisi tertentu.

Di sisi lain, radikalisme juga merambah ke dunia pendidikan, sebagaimana temuan Lembaga Kajian Islam dan Perdamaian (LaKIP) tahun 2010 di Jakarta hasilnya cukup mengejutkan bahwa 48,9\% siswa Jabodetabek menyatakan sepakat dengan aksi radikalisme (Arifin and Rizal, 2017) Pusat Pengkajian Islam dan Masyarakat (PPIM) UIN Syarif Hidayatullah Jakarta tahun 2017 menemukan bahwa 58\% mahasiswa dan siswa mempunyai opini radikal, sedangkan $51,1 \%$ di kalangan muslim, dan 34,4\% di kalangan non muslim memiliki opini intoleransi. Angkanya memang tidak begitu fantastis, namun hendaknya menjadi perhatian bersama. Berikutnya BNPT menginformasikan bahwa terdapat 19 pesantren yang mengajarkan radikalisme dan berpotensi terorisme (Jilan, 2018). Melihat realitas di atas, maka wajar saja jika pesantren selama ini dipersepsi "negatif" yaitu sebagai lembaga pendidikan yang menyebarkan paham radikal, akhirnya berdampak pada berkurangnya animo masyarakat menyerahkan anaknya ke pesantren.

Hakikatnya Islam adalah agama moderat, ramah, toleran, damai dan saling menghargai. Islam memberikan ruang gerak yang luas kepada pemeluknya untuk mengamalkan ajaran agamanya dengan prinsip menjaga agama, kehormatan, harta benda, keturunan, dan menjaga keharmonisan. Meminjam bahasa Scott Bibbbs bahwa Islam merupakan agama yang memberikan kesempatan kepada individu untuk kontak dengan landasan keberadaan yang imanen dan transenden, memberikan kesempatan untuk mengalami penegasan diri, khususnya pelestarian diri psikis (Gibbs, 2005).

Pesantren sebetulnya merupakan institusi pendidikan Islam yang sangat potensial dalam menginternalisasikan nilai-nilai moderat, karena pesantren merupakan "sub kultur" kehidupan. Kiai, ustad, santri dan masyarakat kehadirannya di pesantren sangat strategis dalam mengawal moderasi pendidikan. Kiai sebagai tokoh utama pesantren, berperan mentransformasikan nilai-nilai Islam moderat dan nilai kepesantrenan yang berbasis agama dan budaya lokal di tengah kehidupan masyarakat. Seagaimana diungkapkan oleh Jazuli Sakho' bahwa tradisi pesantren memiliki narasi menangkal ekstrimisme dan radikalisme, karena pesantren dalam sejarah pembelajaran agama di sebagian besar pesantren memiliki relasi dengan budaya lokal (Sakho, 2018).

Penelitian yang termasuk kategori baru adalah penelitian Toto Suharto tahun 2019. Toto Suharto memotret moderasi dua organisasi terbesar di Indonesia yaitu Muhammadiyah dan Nahdlatul 'Ulama (NU). Fokus kajiannya adalah materi alIslam untuk Muhammadiyah dan Aswaja melalui Lembaga Pendidikan Ma'arif untuk NU. Hasil penelitiannya bahwa meskipun Muhammadiyah dan NU mempunyai perbedaan dalam amaliyahnya, namun mempunyai komitmen yang sama dalam membentuk watak dan karakter keislaman yang moderat. Kemoderatan Muhammadiyah tidak hanya pada pada pendidikan tetapi sampai pada sikap politik yaitu mengambil jalan tengah (Nashir et al., 2019). Keunggulan penelitian ini mampu 
mempertemukan perbedaan dalam satu titik "moderasi", meskipun pada awalnya keduanya sering berbeda pendapat terkait masalah khilafiyah, namun dalam masalah moderasi mempunyai kepentingan yang sama yaitu membumikan moderasi di Indonesia.

Riset-riset sebelumnya terkait moderasi pesantren, lebih pada tataran konsep umum moderasi, sedangkan dalam penelitian ini moderasi menyentuh ke akar-akar pesantren seperti kurikulum, kitab kuning, metode pembelajaran dan kegiatan kepesantrenan. Sehingga posisi penelitian ini sangat strategis dalam melihat lebih dekat moderasi.

Berdasarkan deskripsi latar belakang di atas, tujuan penelitian ini yaitu 1) menganalisis upaya pesantren di Kalimantan Timur dalam membentuk moderasi pendidikan, 2) Menemukan model moderasi pendidikan pesantren di Kalimantan Timur, 3) Menganalisis implikasi moderasi pendidikan pesantren di pesantren Kalimantan Timur. Mencermati masalah di atas, artikel ini membahas upaya pesantren dalam membentuk moderasi pendidikan, model moderasi pendidikan pesantren dan implikasi moderasi pesantren dalam kehidupan.

\section{METODE PENELITIAN}

Penelitian ini adalah penelitian kualitatif dengan menggali data pokok di lapangan (field research). Pendekatannya yaitu teologis, pedagogik dan fenomenologis. Subyek penelitian ini adalah pesantren di Kalimantan Timur sejumlah 103 pesantren (BPS, 2017). Mengingat populasinya cukup banyak, maka penulis membatasi beberapa pesantren dengan kriteria yaitu pesantren terpenuhi lima elemen yaitu kiai, santri, pondok (asrama), masjid dan pembelajaran kitab kuning, jumlah santri minimal 75 santri, dan pesantren yang secara resmi terdaftar di Kementerian Agama. Memperhatikan kriteria di atas, maka yang dipilih menjadi subyek penelitian ini yaitu Pesantren Nabil Husein, Sabilal Rasyad, alHusna, al-Mujahidin Samarinda, Syaichona Cholil, Arsyad al-Banjari Balikpapan, al-
Ikhlas dan Hidayatullah Kabupaten Kutai Timur, Binaul Muhajirin Kabupaten Penajam Paser Utara dan al-Khalil Kabupaten Berau.

Fokus penelitian ini yaitu upaya pesantren dalam membentuk moderasi pendidikan, model moderasi pendidikan dan implikasi moderasi pendidikan pesantren. Sumber data terbagi menjadi dua yaitu sumber data primer dan sekunder. Sumber data primer meliputi pengasuh, pengurus yayasan, dewan asatidz dan santri. Sedangkan sumber data sekundernya yaitu alumni dan masyarakat sekitar. Penggalian data menggunakan teknik wawancara mendalam (in-depth interview), observasi, dan dokumentasi. Secara umum teknis analisis data dengan langkah-langkah pengelompokan, pemilahan, pengkategorian dan pemaknaan. Kemudian dilakukan refleksi untuk menemukan hubungan antar data dan pemaknaan sesuai dengan fakta di lapangan. Analisis reflektif digunakan juga untuk merefleksikan fenomena pembentukan moderasi pendidikan, mencari model dan implikasinya. Setelah data dianalisis, maka untuk menjamin bahwa data shahih dan valid, maka perlu diuji dengan triangulasi baik teori, sumber maupun waktu.

\section{HASIL DAN PEMBAHASAN Hasil Penelitian}

\section{Upaya Membentuk Moderasi Pendidikan Pesantren}

Moderasi pendidikan mempunyai peran sangat strategis dalam membentuk watak dan karakter anak bangsa. Moderasi pendidikan setidaknya ditandai dengan diterapkannya demokrasi pendidikan, adopsi hukum Islam pada dunia politik, hubungan yang harmonis dengan penduduk non muslim, menghargai hak-hak masyarakat minoritas dan gender (Yenigün, 2016). Membentuk moderasi dalam pendidikan (pesantren) tidaklah mudah, perlu kecermatan dan keseriusan. Berdasarkan hasil wawancara dan observasi didapat bahwa upaya pesantren dalam membentuk moderasi pendidikan yaitu:

Pertama, pesantren menolak segala bentuk ekstrimisme dan radikalisme. Upaya ini dilakukan dengan meningkatkan 
kesadaran yang tinggi bagi warga pesantren. Sehingga moderasi pendidikan dijadikan sebagai acuan berpikir, bertindak dan bersikap bagi masyarakat pesantren. Berdasarkan analisis dokumen dan observasi bahwa untuk menangkal radikalisme pesantren melakukan a) mendesain pesantren dalam bentuk pesantren salafiyah; b) memilih ustad yang bebas dari pemahaman radikal; c) mengikuti jejak ulama nusantara yang mewariskan tradisi pesantren moderat seperti Muhammad Arsyad al-Banjari, Syaichona Kholil Bangkalan dan Hasyim Asy'ary Jombang dan sebagainya; d) mengajarkan materi keislaman yang bebas dari potensi radikal; e) mengajarkan ajaran ahl al-Sunnah wa alJamaah; f) menerapkan prinsip-prinsip tawasut, tawazun, tasamuh dan i'tidal; g) menyampaikan sejarah Islam secara obyektif.

Kedua, menumbuhkan sikap terbuka dan fleksibel dalam memahami agama dengan tetap menjaga substansi ajaran alqur'an di tengah perkembangan masyarakat. Sikap keterbukaan akan melahirkan sikap moderat, termasuk pesantren terbuka dengan perkembangan informasi dan teknologi.

Ketiga, mendesain kurikulum moderat. Kurikulum yang bersifat moderat merupakan piranti dalam membentuk moderasi pendidikan. Berdasarkan hasil interview bahwa strategi pesantren dalam mendesain kurikulum moderat dilakukan dengan: a) menyajikan kurikulum kajian keislaman yang dikolaborasikan dengan kurikulum mata pelajaran umum secara seimbang. Dengan kolaborasi kurikulum tersebut, maka masyarakat pesantren tidak hanya mementingkan kajian keislaman, tetapi materi pelajaran umum juga dianggap penting; b) mengintegrasikan tiga sumber kurikulum yaitu kurikulum Kementarian Agama, Kementerian Pendidikan dan Kebudayaan, dan pesantren atau diniyah. Tiga sumber tersebut menunjukkan bahwa pesantren mendesain profil lulusannya sebagai santri yang moderat, mempunyai wawasan kebangsaan, dan keislaman. Sehingga santri berpikir, bersikap dan bertindak moderat sesuai konteks keindonesiaan. Beberapa pesantren yang menjadi subjek penelitian mendesain kurikulumnya terintegrasi dalam pembelajaran termasuk bahan ajar. Misalnya kajian fikih, struktur keilmuannya mengikuti Kementerian Agama, buku pegangannya menggunakan kitab seperti Mabadi' Awaliyah, Safinah a-Najah, Fath al-Qarib. Desain kurikulum semacam ini merupakan distingsi pesantren dalam desain kurikulum; c) pesantren terbuka dan beradaptasi terhadap perkembangan ilmu pengetahuan dan teknologi.

Keempat, memilih materi atau bahan ajar yang moderat. Kitab kuning mempunyai peran sangat strategis dalam membentuk paradigma, pola pikir, pandangan santri terhadap keislaman, kebangsaan dan sosial kemasyarakatan. Kitab yang dikaji merepresentasikan metode berpikir dan pemahaman terhadap ilmu. Mayoritas pesantren lebih suka menggunakan kitab yang mengandung nilai-nilai moderat dengan sebutan al-kutub al-Mu'tabarah. Berdasarkan wawancara dan dokumen yang dikaji ditemukan bahwa kajian fikih pesantren sebagaian besar menggunakan kitab Mabadi' Awaliyah, Safinah al-Najah, Fath al-Qarib, Fath al-Muin, Sabil alMuhtadin. Dalam bidang akhlak tasawuf kitab yang kaji yaitu Akhlaq lil al-Banin, Ta'lim al-Muta'alim, Adab al-Alim wa alMuta'alim, Bidayah al-Hidayah, Minhaj alAbidin, Zurrah al-Nasihin, Risalah Qusyairiyah dan dilanjutkan dengan Ihya Ulum al-Din. Dalam bidang tafsir kitab yang sering dikaji di pesantren yaitu tafsir al Ibris dan tafsir Jalalain.

Kelima, metode pembelajaran moderat. Pesantren mempunyai khazanah metode pembelajaran yang unik, hanya dikenal oleh kalangan pesantren, seperti sorogan, bandongan. Keenam, Memformat kegiatan kepesantrenan dengan nuansa moderat. Pesantren adalah miniatur masyarakat, kehidupan pesantren mencerminkan kehidupan di masyarakat. Praktik moderasi pendidikan dilaksanakan secara kultural yaitu mengalir senafas dengan kehidupan 
pesantren. Dalam pesantren terdapat kegiatan-kegiatan yang mendukung tercapainya tujuan pendidikan pesantren. Kegiatan tersebut berupa ta'lim (pembelajaran), ritual keagamaan, dan sosial kemasyarakatan. Ketujuh, Pesantren melayani santri dengan memperhatikan unsur-unsur pokok pada manusia secara seimbang. Manusia terdiri dari unsur jasmani, akal dan jiwa, Pesantren melayani tiga unsur tersebut dengan seimbang.

\section{Model Moderasi Pendidikan Pesantren}

Moderasi atau wasatyah merupakan sikap jalan tengah antara ekstrim dan liberal. Oleh karena itu, mengedepankan sikap moderat adalah sejalan dengan substansi ajaran Alquran dan hadis.

Penelusuran model moderasi pendidikan di pesantren tidaklah mudah. Penelusuran ini cukup memerlukan waktu, mengingat belum tersedia referensi yang memadai. Sehingga memerlukan kecermatan dan ketelitian pada setiap data yang didapat penulis. Berdasarkan hasil wawancara, observasi dan didukung berbagai data, bahwa model moderasi pendidikan pesantren yaitu:

Pertama, model integrasi. Moderasi pendidikan di pesantren terintegrasi dalam

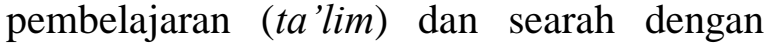
kehidupan pesantren, seperti Pesantren Binaul Muhajirin, Syaichona Kholil, alHusna, al-Mujahidin. Implementasi moderasi pendidikan dengan memberikan pemahaman secara detail kepada santri tentang sejarah beberapa aliran yang ekstrim, radikal dan dampak sosialnya bagi masyarakat. Salanjutnya pesantren menghadirkan materi keislaman yang mengandung nilai-nilai moderat seperti Islam rahmatan lil alamin, cinta damai, menghargai, toleransi, wawasan kebangsaan dan sebagainya. Sebuah fenomena yang menarik bahwa setiap diselenggarakan kegiatan sosial keagamaan seperti Peringatan Hari Besar Islam, dan sejenisnya biasanya pesantren menyelipkan lagu Indonesia Raya dan Subbanul Wathan. Kegiatan semacam ini menjadi rule model bagi pesantren.

Kedua, model terintegrasi dengan ibadah. Penerapan sikap toleransi terhadap khilafiyah ditanamkan melalui ibadah shalat (kaifiyah shalat). Selain itu, bentuk moderasi juga ditunjukkan dengan kepatuhan setiap imam sholat dengan mazhab syariat ibadah masingmasing.

Ketiga, model kolaborasi dengan kegiatan kepesantrenan. Pesantren merupakan subkultur budaya yang sangat kaya tradisi dan budaya. Di antara kegiatan tersebut yaitu haul, imtihan, akhir al-sanah, Istighasah, Yasinan, Tahlilan, ziarah kubur, pembacaan maulid diba', maulid al-Barjanji, pembacaan Ratib, gotong royong, tadarus Alquran dan sebagainya.

\section{Implikasi Moderasi Pendidikan Pesantren}

Implementasi nilai-nilai moderat dalam pesantren secara continue berdampak pada lingkungan pesantren dan masyarakat sekitar. Dampak tersebut memberikan gambaran riil tentang pemahaman moderasi pendidikan yang telah berlangsung di pesantren. Berdasarkan hasil wawancara, bahwa moderasi pendidikan pesantren berimplikasi pada:

Pertama, perkembangan pesantren. Pendidikan yang moderat berimplikasi terhadap perkembangan pesantren. Pada awalnya sebagian masyarakat menganggap negatif terhadap pesantren. Penilaian tersebut berubah menjadi positif karena pesantren mampu menunjukkan sikap moderat, sehingga menjadi salah satu alternatif pendidikan bagi anak-anaknya. Selain itu, santri yang menempuh pendidikan pesantren juga menunjukkan sikap yang moderat. Motivasi teologis "Tidak ada paksaan dalam beragama" merupakan landasan bagi para ustad untuk memahamkam pendidikan yang moderat. Pada saat santri telah menjadi alumni, maka memiliki kesadaran yang tinggi dan bersikap arif pada setiap kondisi. Pada kondisi demikian, kesadaran merupakan sumber motivasi "intern" terbaik dimana motivasi tersebut cenderung tertanam, mengakar dan terimplementasi dalam kehidupan sampai ada doktrin baru yang diterima dan mengubah pemahaman sebelumnya.

Kedua, meningkatnya sikap moderat masyarakat sekitar pesantren. Interaksi kiai, 
ustad, dan alumni dengan masyarakat berpengaruh besar dalam membentuk sikap moderat melalui transfer of knowledge dan transfer of values. Masyarakat yang mendapatkan pendidikan moderat, menjunjung tinggi nilai-nilai egaliter, saling menghargai, toleran sebagaimana dicontohkan oleh Rasulullah Saw.

\section{Pembahasan}

\section{Membentuk \\ Moderasi Pendidikan Pesantren}

Upaya yang dilakukan pesantren dalam membentuk moderasi pendidikan merupakan langkah yang strategis dalam membentuk karakter santri. Penolakan terhadap paham radikal dan ekstrim, berkiblat pada ulama nusantara dan menganut paham Ahl al-Sunah wa al-Jamaah merupakan pintu masuk bagi pesantren dalam membentuk pendidikan yang moderat. Pesantren yang menjadi subyek penelitian memilih Ahl al-Sunah wal al-Jamaah sebagai rujukan ideologinya karena Ahl al-Sunah wa al-Jamaah merupakan sintesa antara doktrin Jabariyah dan Qadariyah, Murjiah dan Mu'tazilah. Sehingga posisinya di tengah-tengah berbagai aliran teologi Islam. Nilai-nilai Aswaja inilah yang melestarikan moderasi di pesantren dan pendidikan Ma'arif NU (Nashir et al., 2019).

Mencermati kuatnya keyakinan Ahl alSunnah wa al-Jamaah dalam membentukan moderasi dapat dipahami bahwa pembentukan moderasi tidak dapat dilepaskan dari keyakinan seseorang. Keyakinan menyangkut tiga dimensi (trilogi) akidah, syariah, dan tasawuf. Pada dimensi aqidah ruang lingkupnya meliputi ketuhanan, alam, sifat Allah, kenabian, sumber kebenaran, sikap manusia. Pada dimensi syariah pada bidang ketuhanan dan kemanusiaan, kemaslahatan individu dan kolektif, idealitas dan realitas, ketegasan dan kelenturan. Sedangkan tasawuf tercermin pada syariat dan hakikat, khauf dan raja', dhahir dan batin serta jasmani dan rohani (Yusuf, 2018). Pemahaman Islam moderat dalam ruang lingkup trilogi keyakinan tersebut merupakan bagian dari keyakinan sebagaimana dinyatakan Abolfathi bahwa pemahaman terhadap Islam yang moderat merupakan bagian dari keyakinan seseorang yang mempunyai pengaruh dalam sikap hidupnya (Abolfathi Momtaz et al., 2012).

Masyarakat pesantren yang notabene beragama Islam merupakan bagian unsur penting dan sangat mewarnai dalam membentuk moderasi pendidikan. Tezcür menyatakan bahwa negara yang mayoritas penduduknya Islam seperti Iran, Mesir dan Indonesia merupakan pendorong yang sangat kuat dalam membentuk moderasi (Tezcür, 2010). Mencermati penelitian Tezcür dapat dipahami bahwa masyarakat beragama Islam memegang peran sangat penting dalam pembentukan moderasi pendidikan. Meskipun tidak sama, penelitian Tezcür mempunyai benang merah dengan hasil penelitian Syamsun Niam yang menyatakan bahwa pesantren merupakan miniatur Islam Indonesia dan miniatur komunitas Muslim Indonesia yang berhasil mengartikulasikan Islam moderat di Indonesia semenjak abad ke-16 M (Ni'am, 2015). Dari sinilah tampak bahwa sesungguhnya akar-akar moderasi pendidikan pesantren hakikatnya sudah ada sebelum istilah "moderasi" lahir.

Pesantren juga berupaya membuka diri terhadap isu-isu kontemporer (al-waqi'iyah) seperti bank, gender, demokrasi, pendidikan multikultural sebagaimana di pesantren Nabil Husin (Khojir, 2014), pluralitas dan kesadaran intercultural (Khojir, Wahid and Fathoni, 2018). Wawasan dan isu-isu kontemporer di pesantren menyebabkan masyarakat pesantren mempunyai sikap yang moderat dan tidak terjebak pada radikalisme dan ekstrimisme.

Dalam membentuk moderasi pendidikan, kurikulum sebagai "jantung" pendidikan, memegang peran sangat sentral. Pilihan pesantren pada kitab-kitab yang bebas dari paham radikalisme (al-kutub al-mu'tabarah) merupakan pilihan yang cerdas. Karena dalam kitab tersebut santri diajak untuk menghargai pendapat lain. Misalnya tentang kesuksesan belajar santri tidak semata-mata ditentukan oleh kecerdasan IQ, banyak variabel yang mempengaruhi yaitu semangat, sabar, modal atau biaya, bimbingan guru, 
waktu dan akhlak. Variabel tersebut harus berjalan seimbang dan bersinergi (Zarnuji, 2018). Deskripsi dalam kitab Ta'lim alMutaalim tersebut tercermin nilai-nilai moderasi dalam kitab kuning. Temuan ini memang sedikit berbeda dengan hasil penelitian Imam Nakha'i terutama terkait fikih jihad. Dalam kajiannya Imam Nakha'i menemukan bahwa kajian kitab kuning berpotensi konflik dan kurang mengapresiasi budaya damai khususnya materi tentang jihad (Nakha'i, 2017). Oleh karena itu menurut Hanafi perlu adanya kajian yang komprehensif tentang jihad agar tidak salah dalam memahaminya (Hanafi, 2013).

Upaya pembentukan moderasi pendidikan tidak sebatas pada kurikulum, tetapi menyentuh sampai pada metode pembelajaran. Metode pembelajaran khas pesantren seperti sorogan, bandongan, lalaran, nadhaman, muthala'ah, takrar, syawir, bahs al-Masaail mengandung nilainilai moderasi. Misalnya dalam praktek sorogan santri diberi kewenangan memilih kitab dengan konsultasi pada ustad. Santri tidak dipaksa (ekstrim) oleh ustadnya dan tidak dibebaskan dalam membaca dan memahami kitab, tetapi terdapat jalan tengah (moderat) yaitu berupa kontrol dan bimbingan dalam mempelajari kitab. Contoh lain, misalnya kegiatan bahs al-Masaail (diskusi). Dalam prosesnya sering terjadi perbedaan pendapat, maka sikap yang dibangun yaitu menghormati pendapat sesama santri. Peran kiai atau ustad sebagai pentashih atau penengah (wasit) dalam mendudukkan sebuah persoalan dan tidak ekstrim pada satu pendapat.

Kegiatan kepesantrenan merupakan bagian yang tidak terpisahkan dalam membentuk moderasi pendidikan. Pesantren mempunyai sederetan khazanah kegiatan santri seperti ta'lim (pembelajaran), ritual keagamaan, dan sosial kemasyarakatan. Berbagai kegiatan ritual keagamaan misalnya seperti pembacaan Maulid alDibai, Maulid al-Barjanji dan Maulid alHabsyi, Istiqhasah, Yasinan, Tahlilan, tadarus, ziarah kubur dan sebagainya. Dalam kegiatan tersebut tercermin nilai-nilai moderasi. Seperti dalam ritual pembacaan Maulid Habsyi, tidak ada dominansi santri, semua syair dibaca bersama-sama yang dipimpin oleh seorang santri. Kemudian secara bergantian peserta lainnya membaca dan santri lainnya bertugas menyimak bacaan lainnya. Proses demikian merupakan salah satu menu pokok dalam pesantren dan menjadi kultur yang dibangun atas dasar kebersamaan dan kesetaraan. Meskipun kegiatannya sederhana dan bersifat teosentris dalam nuansa ukhrawi, nilai-nilai moderasi tampak dengan mengedepankan nilai-nilai keikhlasan, hikmat, kearifan, kesederhanaan, kolektivitas, mengatur kegiatan bersama, kebebasan terpimpin, mandiri, dan restu kiai. (Nafis, 2008). Di sinilah nilai luhur pesantren yang merupakan penyangga moderasi dalam pendidikan.

Termasuk dalam upaya pembentukan moderasi pendidikan adalah pesantren memperhatikan unsur-unsur pokok manusia yang terdiri atas akal, jiwa dan jasmani. Ketiganya mendapatkan pelayanan "seimbang" yang disusun dalam kegiatan kepesantrenan. Schedule kegiatan juga mempertimbangkan unsur-unsur pokok pada manusia. Seperti kegiatan ta'lim, kemasyarakatan, zikir, olahraga, dan istirahat. Keseimbangan tersebut menunjukkan adanya kehidupan yang moderat dalam pesantren. Di sinilah letak penerapan prinsip-prinsip moderasi Pendidikan Islam (Kamrani, 2015).

Secara garis besar bahwa membentuk moderasi pendidikan pesantren juga sejalan dengan karakteristik moderasi pendidikan Islam. Menurut Toto Suharto, karakteristik moderasi lembaga pendidikan Islam tercermin dalam pendidikan damai yaitu menghormati hak asasi manusia dan transformasi sosial; (b) pendidikan yang mengembangkan keterampilan kewirausahaan dan hubungan baik dalam dunia industri; (c) menganggap visi kenabian Islam, termasuk humanisasi, pembebasan, dan transendensi untuk transformasi sosial; (d) memuat ajaran toleransi dalam kehidupan keagamaan dan pluralisme; (e) mempromosikan Islam moderat di Indonesia; 
(f) menyeimbangkan wawasan intelektual, spiritual dan keterampilan; (g) lulusan ulama-intelektual; (h) mengusulkan solusi untuk masalah saat ini dalam pendidikan, termasuk dualisme dan metode pengajaran dan pembelajaran; (i) menekankan kualitas pendidikan secara komprehensif, dan (j) mendorong penguasaan bahasa asing (Suharto, 2017).

\section{Model Moderasi Pendidikan Pesantren}

Model moderasi pendidikan pesantren secara garis besar ada dua model yaitu integrasi dan kolaborasi. Model integrasi terlihat dalam integrasi kegiatan

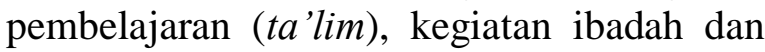
kegiatan kepesantrenan. Jika dikaitkan dengan model penciptaan suasana baru dalam lembaga pendidikan terdapat beberapa model seperti model terstruktur dan model kultural. Model integrasi mirip dengan model terstruktur, artinya model moderasi masuk dalam pembelajaran pesantren. Sedangkan kolaborasi merupakan perpaduan antara kegiatan ritual keagamaan dan sosial kemasyarakatan dalam pelaksanaan moderasi. Implementasi nilai-nilai moderasi seperti keseimbangan, kerukunan, bersikap lurus dan tegas, toleransi, berpikir dinamis dan inovatif, berkeadaban Islam, demokrasi, dan menghargai agama lain dipraktikkan sejalan dan bersinergi dengan kehidupan pesantren. Implementasi nilai-nilai tersebut semakin mempertegas hasil penelitian Halil Ibrahim Yenigün bahwa moderasi pendidikan ditandai dengan diterapkannya demokrasi pendidikan, adopsi hukum Islam pada dunia politik, hubungan yang harmonis dengan penduduk non muslim, serta menghargai hak-hak masyarakat minoritas dan gender (Yenigün, 2016). Nisa Islami juga menemukan hal yang sama tentang nilai-nilai moderasi dalam pendidikan Islam (Islami and Aziz, 2018).

Beberapa model tersebut tidak dapat dilepaskan dari karakteristik kehidupan pesantren yang erat dengan budaya dan tradisi lokal. Sehingga moderasi pendidikan berjalan secara natural tanpa gejolak yang berarti. Hal ini seirama dengan ungkapan Jazuli Sakho' bahwa tradisi pesantren mempunyai cara khas dalam menangkal ekstrimisme dan radikalisme, karena pesantren memiliki relasi dengan budaya lokal (Sakho', 2018). Statemen Sakho' semakin memperkuat temuan Zuli Qadir bahwa moderasi Islam di Indonesia merupakan akomodasi, kolaborasi, toleran terhadap perbedaan suku dan budaya yang ada di Indonesia (Qodir, 2016). Demikian pula hasil penelitian Mutawali bahwa konsep moderasi dalam masyarakat mengkristal pada prinsip keseimbangan, toleransi, musyawarah, keadilan. Konsep tersebut melahirkan kondisi yang harmonis dalam keberagaman agama dan budaya di masyarakat (Mutawali, 2016).

\section{Implikasi Moderasi Pendidikan Pesantren}

Berdasarkan

hasil

penelitian

sebagaimana penulis paparkan di atas bahwa moderasi pendidikan pesantren mempunyai beberapa implikasi yaitu berubahnya penilaian masyarakat terhadap pesantren dari semula negatif menjadi positif. Fenomena tersebut dapat dipahami bahwa tidak semua pesantren mengajarkan nilai-nilai radikal dan ekstrim, hanya beberapa pesantren yang diduga mengajarkan nilai radikal dan berpotensi terorisme (Jilan, 2018). Berubahnya penilaian tersebut mempunyai dampak yang positif yaitu kembali meningkatnya animo masyarakat terhadap pesantren.

Moderasi pendidikan pesantren juga berimplikasi pada masyarakat sekitar, yakni mereka mengenal dan sekaligus mempraktikkan nilai-nilai moderasi melalui komunikasi yang intens antara warga pesantren dan masyarakat sekitar. Kiai, ustad, santri dan alumni merupakan agen dalam membumikan nilai-nilai moderasi melalui kegiatan yang melibatkan masyarakat seperti haul, akhir al-sanah, kerja bakti bersama, majelis ta'lim dan sebagainya. Fenomena tersebut selaras dengan pernyataan Karyanto bahwa salah satu penunjang terciptanya moderasi di masyarakat adalah dengan adanya interaksi pesantren dan aktor di dalamnya dengan masyarakat (Karyanto, 2019). 
Mencermati pendidikan pesantren yang menerapkan nilai-nilai moderasi, maka pesantren semakin dekat dengan masyarakat, dan pesantren menjadi rujukan terutama dalam masalah ibadah dan sosial keagamaan. Di sinilah letak kekuatan pesantren, bahwa pesantren mampu eksis karena dapat beradaptasi dengan berbagai situasi dan kondisi termasuk budaya lokal dengan tetap menjaga substansi ajaran agama Islam dengan tidak kehilangan jati dirinya. Sejalan juga dengan hasil penelitian Prasojo bahwa kearifan lokal yang beradaptasi dengan Islam mampu membuat masyarakat hidup harmonis dalam bingkai keragaman suku, adat-istiadat dan budaya (Prasojo, Elmansyah and Masri, 2019).

\section{KESIMPULAN DAN REKOMENDASI}

Berdasarkan pembahasan di atas dapat disimpulkan bahwa upaya pesantren dalam membentuk moderasi pendidikan melalui: pemberian pemahaman kepada warga pesantren tentang segala bentuk ekstrimisme dan radikalisme karena hal tersebut bertentangan dengan nilai-nilai agama Islam dan kemanusiaan, menumbuhkan sikap keterbukaan, fleksibilitas dalam memahami agama dengan tetap menjaga substansi ajaran alqur'an di tengah perkembangan masyarakat, memilih bahan ajar atau kitab yang bebas dari nilai-nilai radikalisme, mendesain kurikulum moderat dengan cara mengakomodasi ilmu agama dengan ilmu umum, mengolaborasikan antara kurikulum Kementerian Agama, Kementerian Pendidikan dan Kebudayaan, dan diniyah (pesantren), mendesain metode pembelajaran yang moderat, memformat kegiatan kepesantrenan dengan nuansa moderat, pesantren melayani santri secara seimbang baik dalam aspek religius, jiwa, jasmani, akal dan keterampilan.

Model moderasi pendidikan pembelajaran, kegiatan keagamaan dan ibadah, serta kolaborasi dengan kultur pesantren. Implikasi moderasi pendidikan di pesantren yaitu pertama, persepsi positif masyarakat terhadap pesantren dan berkembangnya pesantren dengan indikator bertambahnya animo masyarakat. Kedua, pesantren menjadi rujukan bagi masyarakat dalam menyelesaikan problem terutama yang berkaitan dengan keagamaan dan pendidikan. Ketiga, meningkatnya kesadaran sikap moderat bagi masyarakat.

Berdasarkan temuan di atas, beberapa hal yang perlu direkomendasikan, pertama, pesantren hendaknya memperkuat nilai-nilai moderasi pendidikan, karena pesantren merupakan aset bangsa. Kedua, pemerintah sebaiknya terus memantau dan mendorong terwujudnya moderasi pendidikan di pesantren. Ketiga, para akademisi hendaknya memberikan perhatian tentang kajian pesantren khususnya masalah moderasi.

Temuan ini dapat menjadi refleksi bahwa jika pesantren dekat dengan nilai-nilai moderat, maka didekati oleh masyarakat, bahkan menjadi referensi dalam persoalan keagamaan, pendidikan dan sosial bahkan sampai persoalan ekonomi dan politik. Sebaliknya jika pesantren mengusung nilainilai radikal dan tidak sejalan dengan substansi ajaran agama Islam, maka dijauhi oleh masyarakat.

\section{REFERENSI}

Abolfathi Momtaz, Y. et al. (2012) 'Moderating effect of Islamic religiosity on the relationship between chronic medical conditions and psychological well-being among elderly Malays', Psychogeriatrics. Wiley Online Library, 12(1), pp. 43-53.

Arifin, Z. and Rizal, S. (2017) 'Menangkal Radikalisme di Sekolah', Journal of Education, Social and Religious, Vol 12(1), p. 80.

Azca, M. N., Ikhwan, H. and Arrobi, M. Z. (2019) 'A Tale of Two Royal Cities: The Narratives of Islamists' Intolerance in Yogyakarta and Solo', Al-Jami'ah: Journal of Islamic Studies, 57(1), pp. 2550.

BPS (2017) Laporan Statistik Provinsi Kalimantan TImur, 2018. Available at: www.bps.go.id (Accessed: 25 January 2020). 
Freedman, A. L. (2009) 'Civil society, moderate Islam, and politics in Indonesia and Malaysia', Journal of Civil Society. Taylor \& Francis, 5(2), pp. 107-127.

Gibbs, S. (2005) 'Islam and Islamic extremism: An existential analysis', Journal of Humanistic Psychology. Sage Publications Sage CA: Thousand Oaks, CA, 45(2), pp. 156-203.

Hanafi, M. M. (2013) 'Moderasi Islam: Menangkal Radikalisme Berbasis Agama', Jakarta: Pusat Studi Al-Qur'an.

Herman, A. and Nurdiansa, J. (2010) 'Analisis Framing Pemberitaan Konflik Israel', Jurnal Ilmu Komunikasi, Vol 8, pp. 154-158.

Islam, T. and Khatun, A. (2015) "'Islamic Moderation" in Perspectives: A Comparison Between Oriental And Occidental Scholarships', International Journal of Nusantara Islam, 3(2), pp. 69-78.

Islami, N. and Aziz, S. (2018) 'Strengthening of Islamic Moderation in Kindergarten Darul Qur'an Al-Karim Karangtengah Baturraden Banyumas 2017-2018', Cendekia: Jurnal Kependidikan Dan Kemasyarakatan, 16(1), pp. 63-82.

Jilan, B. (2018) Pesantren dan Radikalisme. Available at: https://www.uinjkt.ac.id/id/pesantrendan-radikalisme/ (Accessed: 20 January 2020).

Kamal, R. (2017) 'Internalization of moderate Islamic values in education', Islamic Studies Journal for Social Transformation, pp. 67-80.

Kamrani (2015) 'Islam Wasathiyah dan Perspektif Pendidikan Islam', in Sarasehan Ulama Se-Kalimantan Selatan di Banjarmasin. Banjarmasin, p. 4.

Karyanto, H. (2019) 'Peran Pondok Pesantren dalam Masyarakat Modern', Jurnal Pendidikan Edukasia, Vol 1(No 1), p. 15.

Khojir, K. (2014) 'Penanaman Nilai-Nilai Multikultural: Studi Kasus Pada Pesantren Nabil Husein Samarinda Kalimantan Timur', Dinamika Ilmu,
14(1), pp. 65-80.

Khojir, Wahid, D. and Fathoni, S. (2018) 'Religion and Culture Integration in Kutai Communities (Intereligious and Intercultural Peacebuilding Model', Jurnal Al-Ulum, p. 501.

Kusmira, D. (2018) 'Moderatism of Pesantren Education In Indonesia', Jurnal Ilmiah Pesantren, 4(2).

Levin, B. (2015) 'The original web of hate: Revolution Muslim and American homegrown extremists', American Behavioral Scientist. Sage Publications Sage CA: Los Angeles, CA, 59(12), pp. 1609-1630.

Mutawali, M. (2016) 'Moderate Islam in Lombok: The Dialectic between Islam and Local Culture', Journal of Indonesian Islam, 10(2), pp. 309-334.

Nafis, M. M. (2008) 'Pesantren dan Pluralisme: Upaya Modernisasi Pendidikan Pesantren Menuju Masyarakat Madani', INSANIA: Jurnal Pemikiran Alternatif Kependidikan, 13(2), pp. 243-270.

Nakha'i, I. (2017) 'Relasi teks keilmuan pesantren dan budaya damai', EDUKASI: Jurnal Penelitian Pendidikan Agama dan Keagamaan, 4(3).

Nashir, H. et al. (2019) 'Muhammadiyah's Moderation Stance in the 2019 General Election: Critical Views from Within', Al-Jami'ah: Journal of Islamic Studies, 57(1), pp. 1-24.

Ni'am, S. (2015) 'Pesantren: the miniature of moderate Islam in Indonesia', Indonesian Journal of Islam and Muslim Societies, 5(1), pp. 111-134.

Nurhisam, L. (2016) 'Islam Nusantara: A Middle Way?', SHAHIH: Journal of Islamicate Multidisciplinary, 1(2), pp. 167-177.

Prasojo, Z. H., Elmansyah, E. and Masri, M. S. H. (2019) 'Moderate Islam and the social construction of multi-ethnic communities in the hinterland of West Kalimantan', Indonesian Journal of Islam and Muslim Societies, 9(2), pp. 217-239.

Qodir, Z. (2016) 'Islam Nusantara as 
Moderatand Tolerant Islam: a Literature Research', Jurnal Pendidikan Islam, Nusantara Islamic Education,(5), 1, pp. 2356-3877.

Sakho, J. (2018) Kedekatan Tradisi Pesantren dengan Budaya Lokal dinilai Menghasilkan Narasi yang bisa Menangkal Pengaruh Radikalisme. Available at: https://tirto.id/tradisipesantren-disebut-punya-narasi-

penangkal-radikalisme-cLaA (Accessed: 12 January 2020).

Suharto, T. (2017) 'Indonesianisasi Islam: Penguatan Islam Moderat dalam Lembaga Pendidikan Islam di Indonesia', Al-Tahrir: Jurnal Pemikiran Islam, 17(1), pp. 155-178.

Tezcür, G. M. (2010) 'The moderation theory revisited: The case of Islamic political actors', Party Politics. SAGE Publications Sage UK: London, England,
16(1), pp. 69-88.

Wahyudhi, N. (2015) 'The Pattern of Islamic Moderate Movement in Java under Political Fluctuations in Early 20th Century', International Journal of Nusantara Islam, 3(2), pp. 47-60.

White, J. T. (2012) 'Beyond moderation: dynamics of political Islam in Pakistan', Contemporary South Asia. Taylor \& Francis, 20(2), pp. 179-194.

Yenigün, H. I. (2016) 'The political and theological boundaries of Islamist moderation after the Arab Spring', Third World Quarterly. Taylor \& Francis, 37(12), pp. 2304-2321.

Yusuf, A. (2018) 'Moderasi Islam dalam Dimensi Trilogi Islam (Akidah, Syariah, Dan Tasawuf', Jurnal Pendidikan Agama Islam, Vol 3(No 2).

Zarnuji, B. (2018) Ta'lim al-Mutaalim.

\section{Article Metadata:}

Khojir. (2020). Moderation of Islamic Boarding School Education in East Kalimantan. Ta'dib, 23 (1), 95-106. http://dx.doi.org/10.31958/jt.v23i1.1945

Keywords: Moderation, Education, Pesantren and Radicalism Coresponding author: Khojir, IAIN Samarinda, khojir@iain-samarinda.ac.id 